\title{
DA BIOPOLÍTICA À NECROPOLÍTICA: VARIAÇÕES FOUCAULTIANAS NA PERIFERIA DO CAPITALISMO*
}

\author{
FROM BIOPOLITICS TO NECROPOLITICS: FOUCAULTIAN VARIATIONS ON THE PERIPHERY OF \\ CAPITALISM
}

Leomir Cardoso Hilário**

\section{RESUMO}

O objetivo deste artigo é apresentar e contextualizar uma ferramenta de análise de autoria do filósofo e cientista social camaronês Achille Mbembe como atualização da crítica social foucaultiana para fenômenos da periferia do capitalismo, em específico aqueles que aludem a uma passagem da biopolítica - a produção da vida e da subjetividade adequadas à forma social capitalista - para a necropolítica, isto é, uma política centrada na produção da morte em larga escala, característica de um mundo em crise sistêmica.

PALAVRAS-CHAVE: Biopolítica. Necropolítica. Michel Foucault. Achille Mbembe. Periferia.

\section{ABSTRACT}

This paper aims to present and contextualize Cameroonian political scientist Achille Mbembe's tool of analysis as an update of Foucault's social critique to phenomena from the periphery of capitalism, particularly those that allude to a transition from biopolitics - the production of life and subjectivity suited to the social capitalist way - to necropolitics, i. e., a policy centered in the production of death in a large-scale, a characteristic of a world in a systemic crisis.

KEYWORDS: Biopolitics. Necropolitics. Michel Foucault. Achille Mbembe. Periphery.

\footnotetext{
* Este texto é uma versão revisada, ampliada e aprofundada de uma conferência ministrada na Universidade Nacional Autônoma de Querétaro, por ocasião da abertura do Seminário de Estudios Críticos de la Cultura, em junho de 2015, cujo título foi “Teoría crítica desde la periferia: capitalismo, violencia y necropolítica".

** Doutorando em Psicologia Social pela Universidade Estadual do Rio de Janeiro (PPGPS-UERJ), com doutorado-sanduíche (PDSE) na Universidade Nacional Autônoma do México (UNAM), bolsista FAPERJ. Email: leomirhilario@yahoo.com.br.
} 
As predições históricas sobre o destino da sociedade burguesa foram confirmadas. No sistema econômico do livre mercado, que levou a humanidade a descobertas de economia de trabalho e finalmente subsumiu-os numa formula matemática global, as máquinas, sua cria específica, tornaram-se meios de destruição não apenas no sentido literal: elas tornaram não o trabalho, mas os trabalhadores supérfluos. (HORKHEIMER, 1990, p. 130-131).

Produzir uma reflexão teórica profunda e radical em tempos de regressão social é a tarefa mais fundamental da chamada teoria crítica da sociedade ou Escola de Frankfurt, como é mais conhecida. Após o breve intervalo histórico dos chamados trinta anos gloriosos, entre 1945-1975, o contexto mundial se assemelha àquele analisado por nomes como Max Horkheimer, Theodor Adorno e Herbert Marcuse, dentre outros. Em vez da ampliação de direitos individuais e políticos, aliados com o crescimento econômico estável - dois pilares constitutivos do arranjo do Estado de Bem-Estar Social - entrou em cena um período de regressão histórica: no plano dos direitos adquiridos, o neoliberalismo promove a retirada de cada um deles, e, no plano da economia, as crises se sucedem com intervalos cada vez menores.

Diante de um tal quadro, recuperar a radicalidade na crítica social é urgente. Argumentei, em outros lugares ${ }^{1}$, por entender que o pensamento crítico não está circunscrito geograficamente e tampouco submetido à camisa de força germânica, que a obra de Michel Foucault pode ser considerada como desenvolvimento da teoria crítica na segunda metade do século XX. No meu entender, Foucault recupera a crítica radical dos mecanismos de poder do capitalismo que se ausentou das análises dos representantes institucionais da Escola de Frankfurt, como Jürgen Habermas e Axel Honneth.

Defendo, também, a possibilidade e pertinência de uma crítica radical adequada ao século XXI como uma forma de teoria crítica periférica, isto é, uma teoria crítica do capitalismo efetuada desde a periferia como uma boa tentativa de compreensão do mundo atual. Vigora hoje em dia, ainda, certa concepção municipal da teoria crítica, da qual o título Escola de Frankfurt é um sintoma. Como se apenas fosse possível fazer teoria crítica em língua ou território alemão, ou no máximo a partir do centro europeu.

\footnotetext{
${ }^{1}$ Mais especificamente em "Michel Foucault e a Escola de Frankfurt: reflexões a partir da obra Crítica do poder, de Axel Honneth", em Trans/Form/Ação, Marília, v. 35, n. 3, pp. 157-188, Dez. 2012; bem como em "Crítica, Razão e Sociedade: convergência e paralelismo entre Foucault e Adorno \& Horkheimer”, em Fractal: Revista de Psicologia, v. 26, n. 3, pp. 877-900, Set./Dez. 2014.
} 
Embora ainda relativamente desconhecido no Brasil, o historiador e cientista político camaronês Achille Mbembe, a meu ver, condensa em sua noção de necropolítica tanto a tarefa de resgatar a potencialidade crítica quanto a de exercê-la a partir da periferia do capitalismo. Por isso, meu objetivo neste artigo é apresentar e contextualizar esta noção. Com esta finalidade, primeiro apresento um suposto déficit periférico existente na obra de Foucault por meio da posição do historiador italiano Domenico Losurdo (II), em seguida exponho sucintamente o conceito de biopolítica em Foucault, ligando-o ao contexto de expansão e consolidação do capitalismo (III) e, por fim, passo para a questão da crise sistêmica atual e de como a necropolítica se apresenta como a forma da política adequada ao declínio da forma social capitalista, no sentido de exercer a função de manter esta sociedade minimamente firme numa época marcada por sua decomposição (IV e V).

\section{II}

Em alguns momentos de sua vasta obra, o historiador italiano Domenico Losurdo (2011, p. 228) sublinha o fato de que a crítica social foucaultiana permanece presa ao continente europeu, de tal modo que "o colonialismo e a ideologia colonial estão amplamente ausentes na história do mundo moderno e contemporâneo reconstruída pelo filósofo francês". Losurdo enfatiza o modo equivocado, a nível histórico, como Foucault (1999, p. 73) situa, no curso É preciso defender a sociedade, o aparecimento de um Estado racista somente com o Terceiro Reich, ao afirmar que "o surgimento do racismo de Estado [deve ser colocado] no início do século XX”.

O historiador italiano dá como exemplos os abolicionistas que queimaram a Constituição Americana em praça pública por esta consagrar a escravidão racial; e a recriminação, também por parte dos abolicionistas, em relação à lei dos escravos fugitivos de 1850, que tornava passível de punição não só aquele que tentasse esconder ou ajudar o negro perseguido por seus legítimos proprietários, mas também quem não colaborasse para sua captura. Para Losurdo (2006), portanto, a White supremacy foi uma forma de Estado racista que não só antecedeu o nazismo como lhe forneceu a base, de modo que se poderia afirmar o nazismo como projeto da White supremacy levada a cabo a nível planetário.

Essa forma, inclusive, desmentiria o juízo foucaultiano, expresso em Vigiar e Punir, segundo o qual "a grande ritualização pública da morte desapareceu a partir do final do século 
XIX” (FOUCAULT, 1999, p. 295), uma vez que, nas primeiras décadas do século XX, o linchamento de negros era organizado como espetáculo de massa, anunciado pela imprensa local, a que são chamados todos os cidadãos. Losurdo ainda critica frontalmente o silêncio de Foucault, naquele curso, em relação ao apartheid em vigor na África do Sul, em 1976: "Foucault não dedica nenhuma atenção à história dos povos coloniais ou de origem colonial" (LOSURDO, 2011, p. 229).

A julgar pela avaliação do historiador italiano, Foucault aparece como pensador eurocêntrico e de pouca serventia para a realidade da periferia do capitalismo. Após estabelecer essa argumentação, Losurdo, em vez de olhar para a periferia e ver o que fizeram com Foucault, mira ao centro e critica Antônio Negri e Michael Hardt. De certa forma, ele parece cometer o mesmo erro que criticou na análise foucaultiana: olha para o centro e esquece da periferia quando avalia o legado de Foucault.

Eu gostaria de pavimentar um outro caminho neste artigo, ou seja, após reconhecer a inegável pertinência desta crítica, pretendo olhar para a periferia e analisar os modos pelos quais os dispositivos de análise foucaultianos funcionam ou não. Por isso, opto por tomar um caminho diverso do de Losurdo, embora por ele influenciado, isto é, em vez de analisar autores inspirados em Foucault no centro do capitalismo que reproduziriam seu eurocentrismo, vou tentar focalizar um autor situado na periferia do capitalismo e mostrar como ele subverte a ordem das coisas apresentada por Losurdo: pois este autor faz com que um pensador supostamente eurocêntrico como Foucault elucide questões periféricas contemporâneas.

Portanto, esta breve exposição dos argumentos de Losurdo me serve como introdução e ponto de partida, pois é justamente a partir da periferia do capitalismo que emerge uma leitura inovadora como a do filósofo e cientista social camaronês Achille Mbembe, a qual faz com que os conceitos foucaultianos sirvam à análise das atuais formas de poder em voga na periferia do capitalismo, adequada à descrição e explicação de processos de barbárie em curso em países como o Brasil e o México.

Penso que a análise de Losurdo é bastante pertinente, pois é o que se pode chamar de visada periférica que lhe permite realizar tais críticas a Foucault. No entanto, meu objetivo neste artigo é tentar ir com e para além dessa crítica, escapando da armadilha da conclusão segundo a qual Foucault seria dispensável para o pensamento crítico periférico devido ao seu eurocentrismo. 
A crítica de Losurdo em relação a Foucault me forçou a repensar a pertinência da crítica foucaultiana para a atualidade, no sentido de sua eficácia em relação à análise de processos de poder na periferia. Os "pós-foucaultianos", se assim posso denominá-los, que procuram atualizar a crítica social foucaultiana não são poucos: Christian Laval, Pierre Dardot, Thomas Lemke, Stéphane Legrand, Byung-Chul Han, Nikolas Rose etc. No entanto, foi ao conhecer a obra de Achille Mbembe que entendi ser possível contornar a crítica de Losurdo e continuar, com um só gesto, na defesa da pertença foucaltiana ao campo teórico crítico como também à possibilidade de exercício periférico da teoria crítica, além de abrir caminho para a compreensão das consequências produzidas no quadro de uma sociedade regressiva marcada por uma crise estrutural.

\section{III}

Em um de seus livros mais conhecidos, Vigiar e punir, publicado em 1975, Michel Foucault investiga o modo pelo qual o poder é capaz de produzir subjetividades adequadas às formas sociais, em específico à do capitalismo. Nesse quadro, o corpo é a realidade política por excelência, o meio através do qual o poder se atualiza e se legitima. O poder, para Foucault, é sempre visto a partir de sua microfísica, de sua incidência sobre os corpos individuais em suas práticas cotidianas, isto significa, em uma palavra, que "as relações de poder penetram os corpos" (FOUCAULT, 1994, p. 228).

Para uma forma social cujo objetivo é o da produção incessante de mercadorias, o corpo deve ser constantemente produzido como dócil politicamente e útil produtivamente, o sujeito da produção e a produção do sujeito são duas faces de um mesmo processo. Há, portanto, um paralelismo histórico entre a sociedade de classes e a sociedade disciplinar, como aponta Jacques Bidet (2014). Foucault (2009, p. 164) chama de disciplina isto que "fabrica os indivíduos", esta "técnica específica de um poder que toma os indivíduos ao mesmo tempo como objetos e como instrumentos de seu exercício". Ou, ainda, "estes métodos que permitem o controle minucioso das operações do corpo, que realizam a sujeição constante de suas forças e lhes impõem uma relação de docilidade-utilidade, são o que podemos chamar de disciplinas" (FOUCAULT, 2009, p. 135).

Foucault (2009, p. 133) está aludindo à entrada do corpo numa "maquinaria de poder que o esquadrinha, o desarticula e o recompõe", numa "anatomia política, que é também uma 
mecânica do poder". No que me interessa, trata-se de efeitos de poder que incidem diretamente sobre os corpos individuais. Foucault está pensando numa época de ascensão e expansão do capitalismo, na qual este sistema necessita do maior número de força de trabalho apta para a produção de mercadorias: fazer do corpo uma máquina de produção, por meio de normas, preceitos e proibições, eliminando desvios e anomalias, eis a função histórica das disciplinas.

A disciplina é centrípeta, isto é, ela circunscreve e organiza um espaço no interior do qual os corpos são sujeitados. É formada, então, por instituições disciplinares, tais quais escolas, quartéis, prisões, hospitais etc., responsáveis por formar, disciplinar, corrigir e deixar saudáveis os corpos. Interessa à disciplina o corpo vivo e sendo potencializado cada vez mais, pois é dessa maneira que ele pode produzir mais mercadorias. O poder disciplinar, então, não é um poder de morte, mas um poder de vida, cuja função não é matar, mas operar a imposição da vida. O antigo poderio de morte da soberania é substituído pela "administração dos corpos" e a "gestão calculadora da vida".

Acato aqui a sugestão de Stéphane Legrand (2004, p. 30) segundo a qual existe um "marxismo esquecido de Foucault", na medida em que ele esteve interessado no vínculo coercitivo do corpo com o aparato de produção, numa articulação muito próxima daquela noção marxiana de subsunção real do trabalho. A disciplina não serve somente à reprodução das relações de produção, mas é de fato "um elemento constituinte do modo de produção", algo como uma força produtiva. A conexão me é extremamente importante, porque me permite sugerir que quando o modo de produção entra num registro que lhe permite dispensar uma grande quantidade de força de trabalho, as relações entre corpo e poder se modificam radicalmente. Acompanho também os julgamentos de Robert Nigro (2001) e Étienne Balibar (1989) segundo os quais a obra de Foucault estaria atravessada, de um extremo a outro, por um enfrentamento com Marx, ainda que de modo não sistemático, e que este enfrentamento constitui uma das fontes principais de suas inovações teóricas.

Não obstante esta relação com Marx, o poder não é, no enquadre foucaultiano, algo possuído por uma classe ou Estado, pois está difuso em práticas sociais diversas que implicam saberes, instituições, discursos etc.; também não é algo primordialmente repressivo, já que sua função pode ser a de produzir sujeitos adequados às formas sociais. É como se ele estivesse levantando algo que Thomas Lemke (2004) chama de "hipótese Foucault", ou seja, entendimento do poder não em torno do seu conceito jurídico ou do consenso/contrato, mas 
sim um sistema social em cuja base está a guerra. Assim, o poder é sempre uma forma particular e definida de colisões momentâneas e continuamente repetidas no marco de um número definido de indivíduos. Nas palavras de Foucault (1979, p. 5): “Creio que aquilo que se deve ter como referência não é o grande modelo da língua e dos signos, mas sim da guerra e da batalha. A historicidade que nos domina e nos determina é belicosa e não linguística".

Axel Honneth (2009, p. 240) apontou a existência desse paradigma da luta ou da guerra na crítica social foucaultiana, em que se entende "o social basicamente como um processo ininterrupto de ações estratégicas em conflito permanente”. Uma das questões não respondidas dessa leitura é como pensar as estabilidades que não são produtos automáticos da dominação nem da disciplina. É aqui que Foucault inscreve uma outra dimensão, a saber, o problema do governo ou da governamentalidade.

Em raros momentos de sensibilidade em relação ao tema das crises, Foucault afirmou que as disciplinas perderam parte de sua eficácia na manutenção do poder, de tal modo que nos países industrializados elas entraram em crise, e isto pode significar que em um futuro deveremos nos distanciar da sociedade disciplinar; ele afirmou isto no início da década de 1970 (FOUCAULT, 2001). Alguma coisa mudou na configuração do sistema capitalista, sobretudo na inflexão das décadas de 1960 e 1970, que fez Foucault direcionar suas pesquisas agora para uma outra dimensão. Em outra ocasião, em entrevista a Duccio Trombadori, ele afirmou:

\footnotetext{
Parece-me, com efeito, que através da crise econômica atual e das grandes oposições e conflitos que se desenham entre nações ricas e pobres, pode-se ver o nascimento de uma crise de governo. Por governo, entendo o conjunto das instituições e práticas através das quais se guiam os homens desde a administração até a educação. É esse conjunto de procedimentos, de técnicas, de métodos que garante a orientação dos homens, uns pelos outros, que me parece em crise hoje, tanto no mundo ocidental como no mundo socialista. (FOUCAULT, 2010, p. 345).
}

O problema do governo passou a estar no centro da teoria social foucaultiana, ou seja, os modos de instrumentalizar a conduta e as esferas práticas com a finalidade de controlar indivíduos e coletividades. Seu foco deixa de ser a disciplina dos corpos e passa a ser a segurança das populações. Aqui se trata de produzir a vida também, mas de coletividades. De uma anátomo-política dos corpos a uma biopolítica da população, portanto.

O que me interessa demarcar aqui, antes de me deter na questão da crise, é a argumentação de Foucault que consiste em dizer que "a velha potência da morte em que se 
simbolizava o poder soberano é agora, cuidadosamente, recoberta pela administração dos corpos e pela gestão calculista da vida" (FOUCAULT, 2015, p. 150). Os poderes são exercidos positivamente sobre a vida. Este biopoder, "elemento indispensável ao desenvolvimento do capitalismo", garantiu "a inserção controlada dos corpos no aparelho de produção", ajustando também a população aos processos econômicos (FOUCAULT, 2015, p. 152).

Se Foucault (2015, p. 155) está correto em afirmar que "o homem moderno é um animal em cuja política sua vida de ser vivo está em questão", o que aconteceria se esta forma social moderna passasse a não mais precisar produzir a vida enquanto momento essencial de sua manutenção? Ou seja, se a vida não fosse mais um elemento indispensável? E se a forma social abrisse mão da produção da vida em larga escala?

\section{IV}

Gostaria de esboçar, a grandes traços, a atual crise do capitalismo, para então fundamentar o modo pelo qual todo o sistema sofreu uma mudança significativa. Para dimensionar de maneira sucinta as transformações ocasionadas por essa crise sistêmica e montar uma imagem que facilite sua compreensão, recorro a uma das argumentações de Raul Hilberg (2005) em seu clássico livro acerca da destruição dos judeus europeus. Para ele houve uma progressão lógica das políticas de antissemitismo. Cita, dentre elas, a assimilação/conversão, isto é, a tentativa de converter os judeus em cristãos, cuja mensagem de base era "vocês não podem viver entre nós como judeus", iniciada no século IX em Roma, durante o reinado de Constantino. Esta falhou porque, por exemplo, muitos judeus se declaravam cristãos mas continuavam suas práticas religiosas enquanto judeus.

A segunda seria a expulsão dos judeus, quando se passou a dizer "os judeus não podem mais viver entre nós", desde o século XIII ao XVI. Os judeus da Inglaterra, França, Alemanha, Espanha e Itália passaram a receber o ultimato: converterem-se ou serem expulsos. E a terceira, a verdadeira inovação do fascismo, seria a destruição dos judeus em larga escala. Seria a solução final porque os judeus convertidos poderiam permanecer como judeus e os expulsos poderiam voltar um dia, mas os mortos não reaparecem jamais. Os nazistas "não começaram uma evolução, completaram-na" (HILBERG, 2005, p. 27). 
Eu gostaria de usar esta explicação de Hilberg como um esquema interpretativo para compreender as transformações oriundas da atual crise do capitalismo. Na época de ascensão e consolidação do capitalismo, entre os séculos XVI e XX, a ação foi a de assimilar grandes massas humanas no interior de grandes fábricas de produção de mercadorias (assimilação/conversão). Quando ocorrem transformações técnicas no modo de produção capitalista, e o sistema passa a precisar cada vez menos de força de trabalho, na segunda metade do século XX, a ação é a de expulsar massas humanas, jogar pessoas no desemprego estrutural, empurrá-las para as periferias da cidade, para as prisões ou simplesmente aniquilálas por meio das forças policiais, oficiais ou não (expulsão).

$\mathrm{Na}$ época atual do capitalismo, já não se trata mais de assimilação nem de expulsão, porque o sistema passa a se desfazer das massas humanas em larga escala. Alguma coisa acontece na ordem do sistema que faz com que aquelas imensas massas sejam agora dispensáveis ao seu modo de reprodução e produção de riqueza. Seu caráter irracional encontra sua temporalidade histórica: ainda que a produção de valor seja própria do trabalho vivo, o capital desenvolve cada vez mais aquilo que Marx (1988) chamou de "trabalho morto" (isto é, força de trabalho que se acumula na forma de máquinas) e, assim, passa a descartabilizar sujeitos agora tornado supérfluos, dispensáveis, sobrantes. Este ponto de chegada é a culminação de uma tendência subjacente à própria dinâmica de reprodução social do capitalismo.

Vivemos numa época histórica na qual a própria base do sistema, o trabalho vivo como base da produção de mercadorias, é minada pelo desenvolvimento das forças produtivas que constitui a dinâmica base de sua manutenção. A partir da segunda metade do século XX, o capitalismo entrou numa fase de crise mundial e colapso (KURZ, 1993). Em termos econômicos, isso significa que sua principal fonte, o trabalho, torna-se dispensável devido ao aumento da composição orgânica do capital e aumento da maquinaria. Nos momentos de expansão, a força de trabalho foi racionalizada dentro da atividade produtiva, como no caso das fábricas de automóveis de Henry Ford e no chamado taylorismo. No período dos trinta anos gloriosos, "fazer funcionar o processo de produção de mercadorias era ao mesmo tempo resolver a vida social" (BLANK, 2014, p. 5), incluir números cada vez maiores de trabalhadores. Após a inflexão dos anos 1970, estes dois registros se separam e, nesta encruzilhada, tem-se optado por manter em funcionamento a débil produção de valor às custas da barbarização dos laços sociais. 
Em termos de política, isso se traduz na passagem da biopolítica para uma necropolítica (MBEMBE, 2006). Não mais, então, uma política voltada para a produção da vida - ainda que adequada à forma social, é verdade - e sim uma política cujo objetivo é a aniquilação em larga escala. Aqui a tendência para o "trabalho morto" na produção de valor encontra o "trabalho de morte" da política. Os indivíduos começam a sobrar diante da forma social atual, pois já não são mais rentáveis, não são mais requisitados a dispenderem sua força de trabalho no interior de um processo produtivo amplo. Muito pelo contrário, são expulsos e jogados no mercado informal e precário, nas margens da cidade etc.

Na crítica social foucaultiana, a política se assemelha a um "trabalho de vida", porque o que está em jogo é constantemente produzir a vida, sejam indivíduos dóceis politicamente e úteis produtivamente, sejam populações sadias que garantam as riquezas às nações. No contexto da crise sistêmica como a que vivemos, no qual o Estado de exceção é a regra, a política se converte em "trabalho de morte". Como pensar tal transição?

Nascido em 1957 nos Camarões, Achille Mbmebe é um historiador e cientista político cuja obra possui bastante relação com o chamado pensamento pós-colonial. Em 1982, chegou em Paris para estudar História e Ciência Política na Universidade de Sorbonne, doutorando-se em História em 1989. Publicou alguns artigos em jornais, como no Le monde diplomatique. Publicou o livro De la poscolonie: essai sur l'imagination politique dans l'Afrique contemporaine, em 1999. Foi convidado para ser secretário-executivo do Conselho para o Desenvolvimento da Pesquisa em Ciências Sociais na África (CODESRIA). Em 2011, tornou-se diretor de investigação do Witwatersrand Institute of Social and Economic Research, situado em Johannesburgo. Em resumo: Mbembe é um intelectual público cuja obra está a pleno vapor.

Uma das preocupações de Mbembe é a de produzir, de forma coletiva, um saber e uma epistemologia da África respaldada pelos seus próprios intelectuais, e não unicamente sobre a África, tomando por base intelectuais da Europa. Desta interrogação sobre "a longa noite do mundo africano pós-colonial" surgiu o livro Sortir de la grand nuit - essai sur l'Áfrique décolonisée, publicado em 2010. Por fim, em 2013, ele publica seu livro Crítica da razão 
negra - traduzido pela editora portuguesa Antígona em outubro de 2014 -, talvez a sua obra mais madura, onde ele expõe um programa filosófico amplo.

Este breve panorama serve também para demonstrar a amplitude dos estudos de Mbembe. Neste artigo, tomo como referência somente uma de suas reflexões sobre o que ele chama de necropolítica. Publicado primeiramente em 2003 na revista americana Public Culture, Necropolitcs é o texto seminal dessa noção. Em francês, foi publicado na revista francesa Raisons politiques: estudes de pensée politique em 2006. Em língua inglesa, este ensaio também foi republicado na coletânea "Foucault in an Age of Terror: Essays on Biopolitics and the Defende of Society", organizado por Stephen Morton e Stephen Bygrav, em 2008.

Em espanhol, o texto foi publicado em 2011 pela editora Mesulina, seguido de outro ensaio chamado "Do governo privado indireto". Ambos os textos apresentam uma análise proposta por Mbembe, cuja característica principal é desvelar novas formas de dominação e submissão no continente africano pós-colonial. Apesar do enfoque geográfico delimitado, não é exagero afirmar que a sua análise pode se aplicar ao conjunto da periferia do capitalismo, sobretudo quando percebemos o fenômeno das "massas supérfluas" que vivem num estado de absoluta precariedade, expulsos do arranjo socioeconômico atual e que ocupam as margens das grandes cidades.

Achille Mbembe, apesar de ser relativamente desconhecido no Brasil, tem suas ideias debatidas no México, muito por conta da violência urbana brutal de algumas cidades mexicanas. Exemplo dessa proximidade foi sua conferência chamada "Necropolítica, uma revisão crítica", proferida em 2012 na Universidade Nacional Autônoma do México (UNAM). Eu mesmo somente tomei conhecimento desse intelectual quando, por ocasião do doutorado sanduíche na UNAM no primeiro semestre de 2015, li um artigo do jornalista uruguaio radicado no México chamado Carlos Fazio, num dos jornais de maiores circulação no México, o La Jornada. Nesse artigo, intitulado "La catástrofe que viene”, Fazio utiliza o conceito de necropolítica para refletir acerca dos processos violentos em Tijuana, Torreón e Cidade Juaréz, que consistem em assassinatos, desaparições forçadas, execuções sumárias extrajudiciais etc. Fazio também enfatiza como este "trabalho de morte" é levado a cabo por meio das máquinas de guerra privadas (como milícias, mercenários e companhias de segurança privada). No momento em que li aquele curto artigo, perguntei-me: mas não se passa o mesmo no Brasil? 
Foi isso que me levou ao interesse em ler Achille Mbembe, isto é, por compreender que sua noção de necropolítica possibilita uma análise crítica dos fenômenos de violência próprios da periferia do capitalismo, onde o desfazimento de um débil Estado de Bem-Estar Social se realiza por meio da barbárie numa dinâmica em que a era de crescimento de direitos individuais e políticos é substituída pela fase de declínio e retirada desses mesmos direitos. Toda esta dinâmica de desconstrução do arranjo de Bem-Estar Social é feita também por meio da agudização das tendências que sempre foram a regra na periferia brasileira do capitalismo: exclusão, barbárie e autoritarismo.

$\mathrm{Na}$ verdade, o próprio Mbembe utilizou a noção necropolítica em apenas um de seus textos, depois disso, segundo suas próprias palavras, "seguiu adiante", isto é, sem fazer referências ou aprofundamentos posteriores. Helena Chávez Mac Gregor (2013) argumenta que a necropolítica pode ser vista como uma categoria que permite problematizar a fundamentação da política contemporânea a partir dos modos como se entrelaçam, por um lado, violência e direito e, por outro lado, exceção e soberania.

Neste artigo, quero chamar a atenção para uma das dimensões da noção de necropolítica, a saber, aquela que se refere à "destruição material dos corpos e populações humanos julgados como descartáveis e supérfluos” (MBEMBE, 2012, p. 135). A figura do sujeito supérfluo, l'homme jetable, como defende Bertrand Ogilvie (2012), aquele cuja força de trabalho já não é mais necessária ao modo de reprodução do capital em sua fase atual converte-se em portador de uma vida matável. Literalmente, possui uma "vida sem valor" (AGAMBEN, 2010, p. 134), uma vida indigna de ser vivida. Se a socialização no quadro capitalista se dá pela troca de mercadorias, compra e venda de força de trabalho no seu nível mais fundamental, significa que este sujeito supérfluo está fora, expulso desse circuito. A "vida nua", desprovida de qualquer valor de troca, tal qual o judeu no campo de concentração reduzido a zero e despojado de todos seus valores de uso (brincos, roupas, sapatos, joias etc.), "assinala o ponto em que a biopolítica converte-se necessariamente em tanatopolítica" (AGAMBEN, 2010, p. 138).

A ação política de morte, necropolítica ou tanatopolítica, é a forma política adequada ao capitalismo em crise estrutural, no sentido de que atende aos seus objetivos. Na medida em que a "questão social” já não é mais solúvel no interior das instituições sociais capitalistas, a sua consequente militarização e barbarização aparece como modelo de gestão possível (CASTELO, 2014). Em tempos de crise estrutural, não se trata mais de superá-la, dado o seu 
caráter permanente, e uma vez que o horizonte emancipatório de uma outra forma social possível está ausente, trata-se, então, de empreender um processo de gestão da barbárie enquanto estratégia de manutenção de um mundo em ruínas, como analisa o filósofo crítico brasileiro chamado Marildo Menegat (2012).

\section{VI}

Eu gostaria de fornecer, para finalizar este artigo, dois exemplos do funcionamento da necropolítica na periferia do capitalismo: o primeiro diz respeito à intervenção atual em relação à criminalidade tanto em relação às prisões quanto ao modus operandi da Polícia Militar do Estado do Rio de Janeiro, que consiste em eliminar sistematicamente essa massa supérflua anteriormente citada; e o segundo se refere a um caso mexicano que ganhou apoio internacional, trata-se do assassinato de mais de quarenta estudantes mexicanos por agentes do narcotráfico, porém com claras motivações políticas.

Aquelas instituições disciplinares - escolas, prisões, hospitais etc. - estão definhhando na atualidade, razão pela qual se pode afirmar que as formas de sociabilidade próprias do capitalismo entraram em estágio de decomposição. Vejamos o exemplo da prisão. A população carcerária brasileira cresceu 30\% em 20 anos, de 1990 até 2010, tendo crescido numa taxa 15,7 vezes maior do que a taxa de crescimento da população nacional. Aquela ideia de que o sistema carcerário operava no sentido positivo, isto é, ressocializador, constituindose enquanto espaço no interior do qual os indivíduos que cometiam crimes eram relançados para a sociedade melhores do que ingressaram, hoje é capaz de provocar risos. A prisão se tornou um "armazém de dejetos humanos do mercado" (WACQUANT, 2007 p. 126).

A opinião pública considera plenamente aceitável que as detenções devem deixar de ser temporárias e passar a ser o mais duradouras possível, além de atingir o maior número de pessoas. Se antes, nas fases de ascensão e consolidação do capitalismo, o pensamento era: "vamos enviar o criminoso para a penitenciária de modo que ele seja corrigido e retorne melhor para a sociedade"; hoje, na época de declínio desta forma social, a afirmação é: "vamos armazenar a maior quantidade de massa humana sobrante e perigosa nas prisões, a fim de nos protegermos dela, de nos livrarmos dela o máximo de tempo possível”. Aquela conexão sugerida pelos frankfurtianos Georg Rusche e Otto Krichheimer (2004) entre punição 
e estrutura social se demonstra na atualidade pela correlação entre o recrudescimento e ampliação das penas e o quadro da crise do capitalismo marcado pela regressão.

O fato de que a Polícia Militar do Rio de Janeiro tenha cometido mais de 10 mil homicídios cometidos entre 2001 e 2011, sendo muitas das vítimas menores de 18 anos (MISSE, 2013), parece-me também ser demonstração destes tempos necropolíticos. Como diz Orlando Zaccone (2015, p. 23-24), "a polícia mata, mas não mata sozinha”, ou seja, "existe uma política pública, na forma de razões de Estado, a ensejar os altos índices de letalidade do sistema penal brasileiro, com destaque para aqueles praticados rotineiramente nas favelas cariocas".

A estrutura sombria da morte parece ser uma regra na periferia do capitalismo. No final de 2014, ganhou repercussão nacional o caso em que 43 estudantes de Ayotzinapa foram mortos em Iguala, no México. Uma grande parte da população mexicana refere-se a esse acontecimento como um processo de "desaparición forzosa", ou seja, um ato político que consistiu em sumir com vários corpos sem nenhum rastro. Em vez de ser um caso isolado, é um caso emblemático, porque, segundo uma das revistas de maior circulação no México, a Revista Proceso (edição de 8 de fevereiro de 2015), durante o atual governo de Henrique Pieña Nieto, um mexicano desaparece a cada duas horas.

No caso dos estudantes, eles eram da Escuela Normal Rural Isidro Burgos de Ayotzinapa, filhos de camponeses, em geral alunos com baixos recursos, pobres, com uma tradição de luta e vinculados a uma das mais persistentes organizações estudantis mexicanas, a Federación de Estudiantes Campesinos Socialistas de México (FECSM). Quando foram capturados, em 27 de setembro de 2014, esses estudantes estavam a caminho da Cidade do México para participar de uma manifestação de lembrança ao chamado massacre de Tlatelolco $^{2}$. No município de Iguala, Guerrero, os estudantes foram levados à delegacia central de Iguala por veículos oficiais da política e de lá não se sabe para onde foram. Um tipo de procedimento necropolítico muito parecido com aquele utilizado no que ficou conhecido como "caso Amarildo", em que um indivíduo foi levado por uma viatura oficial e logo depois sumiu, uma “desaparición forzada" à brasileira.

\footnotetext{
${ }^{2}$ Também chamada de Noite de Tlatelolco, refere-se ao dia 2 de outubro de 1968, dez dias antes da abertura dos Jogos Olímpicos, quando na Plaza de las Tres Culturas, em Tlatelolco, Cidade do México, houve um massacre com aproximadamente 40 pessoas mortas. Indico o documentário, dirigido por Carlos Mendoza, chamado “Tlatelolco: las claves de la massacre”, produzido no México em 2003.
} 
A política de morte perpetrada pelos aparatos policiais do Brasil e do México parecem constituir a paisagem da necropolítica atual em vigência na periferia do capitalismo no quadro da crise mundial contemporânea. Com o colapso do desenvolvimentismo para essas nações periféricas, bloqueando, portanto, qualquer transição para uma autonomia nacional, a tarefa da ordem do dia parece ser a de controlar à força os territórios para os quais já não existe futuro promissor. Como sublinhou o crítico literário Roberto Schwarz (1999), o final do século XX se apresentou aos países atrasados como uma época de impossibilidade crescente de que eles se incoroporassem enquanto nações autônomas em relação ao mercado mundial. Ocorre um processo de "desintegração nacional" e o risco é de repetirmos o que ele chamou de "desastre da Abolição", isto é, quando os senhores, ao se depararem com o processo inelutável da modernização brasileira, livraram-se dos escravos e os abandonaram à própria sorte.

Aliás, certa feita, o grande filósofo da racionalidade moderna, Georg Friedrich Hegel, assumiu um ponto cego nas grandes ações totalizadoras do Espírito Absoluto em direção ao progresso. Segundo ele, a sociedade moderna produz um resto que não se integra, ao que ele chamou de plebe. Diante dela, o meio mais eficaz é o de "abandonar os pobres ao seu destino e entregá-los à mendicidade pública" (HEGEL, 1997, p. 209). Tudo se passa como se aquela racionalidade tivesse um resto, a plebe, que não se inscreve em sua lógica. Ou, melhor dizendo, a lógica que consiste numa inclusão total da forma social possui a contraface de um extermínio indireto daqueles que sobram.

Hoje, esta sugestão endossada por Hegel dá uma volta no parafuso, pois já não basta mais deixar a plebe entregue à sua própria sorte, o que implica certa aniquilação passiva das massas sobrantes, mas sim passar a ativamente aniquilá-las por meio da força policial legitimamente ancorada no Estado. Tudo isto sinaliza que ação biopolítica está sendo tendencialmente substituída por uma ação necropolítica.

\section{REFERÊNCIAS}

AGAMBEN, Giorgio. Homo sacer: o poder soberano e a vida nua. Belo Horizonte: Editora UFMG, 2010.

BAILBAR, Étienne. Foucault et Marx: la question du nominalisme. In: Michel Foucault philosophe. Paris: Seuil, 1989.

BLANK, Javier. Acumulação sem legitimação e o recrudescimento da violência estatal. Rio de Janeiro, Revista Epos, v. 5, n. 1, p. 79-98, jun. 2014. 
BIDET, Jacques. Foucault avec Marx. Paris: Le fabrique éditions, 2014.

CASTELO, R. Crise conjuntural e (re)militarização da "questão social" brasileira. Revista Margem à Esquerda, n. 23, pp. 46-51.

FOUCAULT, M. Conversa com Michel Foucault. In: Repensar a política. Rio de Janeiro, RJ: Forense Universitaria, 2010.

FOUCAULT, M. Em defesa da sociedade. São Paulo: Martins Fontes, 2005.

FOUCAULT, M. História da sexualidade: a vontade de saber. São Paulo: Paz e Terra, 2015.

FOUCAULT, M. La société disciplinaire en crise. In: Dits et Écrits, Tomo 2. Paris:

Gallimard, 2001.

FOUCAULT, M. Les rapports de pouvoir passent à l'intérieur des corps In: Dits et écrits. Tomo 3. Paris: Gallimard, 1994, p. 228-236.

FOUCAULT, M. Microfísica do poder. Rio de Janeiro: Edições Graal, 1979.

FOUCAULT, M. Vigiar e punir: nascimento da prisão. Rio de Janeiro: Vozes, 2009.

HEGEL, G. F. Princípios de Filosofia do Direito. São Paulo: Martins Fontes, 1997.

HILBERG, R. La destrucción de los judíos europeos. Madrid: Ediciones Akal, 2005.

HORKHEIMER, M. The Authoritarian State. In: ARATO, Andrew; GEBHARDT, Eike. The Essential Frankfurt School Reader. New York: Continuum, 1990.

KURZ, Robert. O colapso da modernização: da derrocada do socialismo de caserna à crise da economia mundial. Rio de Janeiro: Paz e Terra, 2003.

LEGRAND, S. Le marxisme oublié de Foucault. Actuel Marx, 2004/2, no 36, pp. 27-43.

LEMKE, Thomas. "Marx sans guillemets": Foucault, la gouvernementalité et la critique du néolibéralisme. Actuel Marx, no 36, 2004, pp. 13-26.

LOSURDO, Domenico. Como nasceu e como morreu o "marxismo ocidental". Estudos de Sociologia, Araraquara, v. 16, 2011, pp. 213-242.

LOSURDO, Domenico. El origen norteamericano de la ideología del tercer Reich : guerra preventiva, americanismo y antiamericanismo. Dialéctica, nueva época, ano 30, $\mathrm{n}^{\circ} 38,2006$ pp. 93-116.

LOSURDO, Domenico. Para uma crítica da categoria de totalitarismo. Crítica Marxista, $\mathrm{n}^{\circ}$ 17, 2003, pp. 51-79. 
MAC GREGOR, Helena C. Necropolítica: la política como trabajo de muerte. Ábaco. Revista de Cultura y Ciencias Sociales, no 78, 2013, pp. 23-30.

MARX, Karl. O capital: crítica da economia política. Livro I: o processo de produção do capital. São Paulo: Abril Cultural, 1988.

MBEMBE, Achille. Necropolitics. Public Culture, 15, 2003, p. 11-40.

MBEMBE, Achille. Necropolítica, una revisión crítica. In: GREGOR, Helena Chávez Mac (Org.). Estética y violencia: Necropolítica, militarización y vidas lloradas. México: UNAMMUAC, 2012, p. 130-139.

MENEGAT, Marildo. Estudos sobre ruínas. Rio de Janeiro: Revan, 2012.

MISSE, Michel. Quando a polícia mata: homicídios por "autos de resistência" no Rio de Janeiro (2001-2011). Rio de Janeiro: NECVU; BOOKLINK, 2013.

NIGRO, Robert. Foucault lecteur et critique de Marx. In : BIDET, Jacques; KOUVÉLAKIS, d'Eustache (org.) Dictionnaire Marx Contemporain. Paris: Presses Universitaires de France, 2001.

OGILVIE, B. L'Homme Jetable. Essai sur l'exterminisme et la violence extrême. Paris: Editions Amsterdam, 2012.

RUSCHE, G. ; KIRCHHEIMER, O. Punição e estrutura social. Rio de Janeiro: Revan, 2004.

SCWHARZ, Roberto. Sequências brasileiras. São Paulo: Cia das Letras, 1999.

WACQUANT, L. Punir os pobres: a nova gestão da miséria nos Estados Unidos [A onda punitiva]. Rio de Janeiro: Revan, 2007.

ZACCONE, Orlando. Indignos de vida: a forma jurídica da política do extermínio de inimigos na cidade do Rio de Janeiro. Rio de Janeiro: REVAN, 2015. 